\title{
Research on the Innovation of the Maker space Operation Mode in Zhejiang Colleges Based on the Perspective of the Transfer of Entrepreneurial Tacit Knowledge
}

\author{
Hongli Hu ${ }^{1, a}$, Yuankan $\mathrm{Yu}^{2, \mathrm{~b},{ }^{*}}$ \\ ${ }^{1}$ School of Business Administration, Zhejiang Gongshang University, \\ Hangzhou, Zhejiang, China \\ ${ }^{2}$ School of Business Administration, Zhejiang Gongshang University, \\ Hangzhou, Zhejiang, China \\ ahuhongli2008@126.com, byuyuankan@163.com \\ *Yuankan Yu
}

Keywords: Entrepreneurship, Tacit knowledge, College passenger creation space, Operational model.

\begin{abstract}
In recent years, colleges in Zhejiang Province have kept pace with the times and have increasingly focused on student entrepreneurship training. The results have been less than ideal. In 2014, Premier Li Keqiang began to promote "mass entrepreneurship and innovation". At this time, foreign entrepreneurial ideas gradually affected the country. Major universities in Zhejiang Province began to draw on and innovate. This paper aims to analyze the outstanding and inadequacies of the maker space operation model of colleges in Zhejiang Province, and to come up with the innovation measures of the maker space operation model of Zhejiang colleges that can effectively promote the transfer of hidden knowledge of entrepreneurship, and Help colleges in Zhejiang Province to better conduct entrepreneurship education and cultivate more outstanding entrepreneurial talents.
\end{abstract}

\section{基于创业隐性知识转移视角的浙江高校创客空间运营模式创新研究}

\author{
胡洪力 $1, \mathrm{a}$, 俞远㑆 $2, \mathrm{~b},{ }^{*}$ \\ ${ }^{1}$ 浙江工商大学工商管理学院, 杭州, 浙江, 中国 \\ ${ }^{2}$ 浙江工商大学工商管理学院, 杭州, 浙江, 中国 \\ ahuhongli2008@126.com, byuyuankan@163.com \\ *俞远㑆
}

关键词：创业; 隐性知识; 高校创客空间; 运营模式

中文摘要. 近年来, 浙江省高校与时俱进, 越来越注重对学生的创业培养, 效果却不甚理想。 2014年，李克强总理开始推进 “大众创业，万众创新”，此时国外的创客思想又逐渐影响到 国内，浙江省各大高校对其开始借鉴与创新。本文旨在通过对浙江高校的创客空间运营模式 的研究, 分析其中的优秀之处与不足之处, 得出有效促进创业隐性知识转移的浙江高校创客 空间运营模式创新对策, 帮助浙江高校更好的进行创业教育, 培养出更多出色的创业人才。 


\section{1.引言}

浙江省多年来坚守着创业创新的信念，鼓励创新，注重创业行为，创业创新的文化氛围 浓烈, 创客空间在全省各地如雨后春笋般涌现, 同时, 浙江省也是我国的经济大省，历年的 生产总值（GDP）均位于全国前列，亦为创客空间的发展提供了有力的资金保障。据统计， 目前浙江省内省级创客空间共计 108 个, 主要的创客空间集中在杭州市和宁波市一带。此外, 浙江省内高校众多, 拥有浙江大学、浙江工商大学以及浙江理工大学等诸多国内重点大学, 都已经自办或合办属于自身的创客空间，例如浙江大学的紫金创业元空间、浙江工商大学教 工路创业园、浙江理工大学创业孵化园以及杭州电子科技大学的科技创业园等。

然而，虽然目前浙江省内的各大高校都已经建立起创客空间、创业园等，也取得了初步 的成效，但是目前还处于起步阶段，各大高校正在积极探索道路。一般的创业教育大多以创 业显性知识的传播为主, 隐性知识为辅, 这对于高校学生的创业能力的提高和创业精神的培 养都是远远不够的, 而创业实践中所产生的创业隐性知识如果能够有效的转移到学生身上的 话, 能够强化创业教育效果, 培育更好的创业人才。于此, 本文将基于创业隐性知识转移视 角探讨浙江高校创客空间运营模式创新。

\section{2.文献回顾}

隐性知识的概念最早由英国科学家迈克尔·波兰尼在 1958 年提出，他认为，隐性知识是 深植于个体及其心智模式、难以编码及沟通的知识, 属技巧性、由情景限定、个人独自体验 但“知而不能言者众”的知识，具有高度个人化、难以规范化的特点。

“创客”源于美国，麻省理工学院为个人的创新创造提供了一个不受以往限制（例如个人 难以承受价格的实验器材以及专业的科研人员）的平台一个人实验室, 可以实现个人的创 意，不仅仅是创造，这便是创客空间。从此以后，微软、IBM 以及苹果等诸多企业开始借鉴 这个模式 (杨建新和孙宏斌等, 2015)。创客空间是一个为有创业意愿或者创意的人实现自身 的想法的场所，是追求个人意义与自我价值的新时代下的必然（王芗和黄典贵，2015）。

那么创客空间与隐性知识的联系又在哪里呢? 梁中（2012）认为创业能力的学习过程则 更多的是一种亲自学习的进程, 学习者经过持续的经历累积、吸收和体悟, 最终内化为具有 个体色彩的自我隐性知识。所以, 在创业教育中, 必须抛弃那种只能让学生获得显性知识碎 片的教育方式，而着重构建有利于创业隐性知识生成和转移的教育方式，以促进教育对象对 创业隐性知识的获取与共享。

创客空间能够很好地让学生进行创业实践, 将创业实践中所获得的隐性知识转移到学生 自身中去, 对于隐性知识的转移来讲, 创客空间是一个很好的转移场所。创业能力和创业精 神的发展主要依赖于创业相关的隐性知识的生成与获得，而高校创客空间的运营与发展为创 业隐性知识的生成与成长提供了丰沛的土壤, 促进了隐性知识向大学生的转移, 有效地增进 了高校的创业教育效果, 让大学生在实践中获得知识和能力, 并很好的形成了自己的创业精 神。

\section{3.基于创业隐性知识转移视角的浙江高校创客空间运营模式现状及存在问题分析}

在提出“大众创业、万众创新”之前，浙江省内诸多高校已经建立了自身的创业园，例如 浙江师范大学网络经济创业园、浙江省国家大学科技园、浙江工业大学创业园等。并且在国 务院发布相关文件之后, 全国创客空间遍地开花, 浙江省内诸多高校也开始探求新的创客空 间建立以及运营模式。据统计，目前浙江省内主要的创客空间主要集中在杭州市和宁波市一 带, 根据浙江省 2016 年的认定结果, 省级创客空间共计 108 个, 其中杭州市省级优秀创客空 间 13 家，省级创客空间 30 家，宁波市省级优秀创客空间 3 家，省级创客空间 28 家，杭州市 
占据了将近四成。

\section{1 基于创业隐性知识转移视角的浙江高校创客空间运营模式现状}

目前浙江省内高校创客空间的运营模式主要分为两种，一种是以高校为主体的创客空间 运营模式, 即由高校发起建立, 主要运用的是高校的资源, 高校作为运营主体, 由高校提供 人员进行管理，例如浙江师范大学众创空间、浙江大学紫金创业元空间、浙江工商大学创业 园等; 另外一种是高校和企业联合运营的众创空间模式, 一般而言, 高校提供场所, 水电以 及网络通信等基础设施，而企业会提供相应的管理人员以及部分资金，例如杭州电子科技大 HD-PARK 众创空间、浙江理工大学的“尚十众创空间”以及杭州职业技术学院达利女装学院等。 经过分析，两大模式下的创客空间都具有以下的几大特点:

3.1.1 空间属性

提供低廉甚至免费的基本办公场所、基础设以及和共享的相关器材设备，例如开放实验 室、加工车间、WIFI、电脑、公共会议室以及休闲场所等。创业地点一般由学校内部原有的 场所改建而来或者校外的获得政府一定补贴的低价场所; 水、电以及网络等相关基础设施也 可以得到一定的优惠; 对于创业设备, 比如 3D 打印机、数控切割机床、木工加工中心等相 关的设备则根据具体创客空间的规划而有所不同，但每一个创客空间都拥有不等的相关创业 设备，比如拥有诸多设备的的浙江大学紫金创业元空间。

\section{1 .2 创客定位}

几乎绝大多数创客空间都面向全体在校并且具有创新创业愿望的学生以及应届生，仅仅 接收极少量的社会人士。创业团队一般具有“少而简”属性, 团队人数少, 约为 3-6人, 项目 普遍处于起步阶段, 甚至还停留在假设中。对他们而言, 创客空间与传统的创业对比而言, 门槛更低, 也更加适合当今的大学生创业。

\subsection{3 功能设置}

注重创业想法的孵化和转化, 只要有一定可行的创业想法, 浙江高校创客空间都会提供 条件去实现它, 比如提供创业导师，配置相关课程，为创客空间成员和团队开展技术、管理、 财务、法律等各方面的培训; 提供解读各类优惠政策、政府补贴申请以及知识产权等各项服 务; 帮助开展项目路演, 为创业项目提供可能的人脉帮助和资金来源; 开展项目评估, 对条 件合格的项目给予融资帮助。

\section{1 .4 平台服务}

线上与线下两大方面平台的联动服务，线上通过创业论坛、贴吧、微博、公众号等方式 进行交流与合作，线下通过创业沙龙、创业讲座、创业者俱乐部等方式进行交流与资源对接。 有些高校通过呢相关的创业比赛来促进创客们的交流, 思想的碰撞和融合, 迸射出新的创意 火花。

\section{2 浙江高校创客空间运营模式存在的主要问题}

浙江高校创客空间的构建本应该是通过为创客空间成员提供各项服务，包括资金途径提 供、咨询和培训等, 促进创业隐性知识的生成, 同时通过项目融资、交流平台等为创业隐性 知识提供保障, 然后通过创业实践实现创业隐性知识的转移。然而浙江高校的创客空间没有 充分发挥整个创客空间的各项优势，比如资金渠道、场地、创业专业咨询等，仅仅为创客空 间成员在创业项目实践过程中解决了部分问题, 并未为创业隐性知识的转移提供充足的保障, 建立良好的环境。

\subsection{1 模式缺陷}

以高校为主体的运行模式对于高校的软件以及硬件设备要求比较高, 需要强大的师资力 量以及丰富的创客空间管理经验, 一旦有所缺失, 将会严重影响创客空间的运行, 没有良好 的转移环境, 不适宜创业隐性知识的转移, 浙江工商大学流水苑三楼的创业空间就存在这种 
问题, 没有全面的建设蓝图以及大量相关设备; 而高校与企业联合的运行模式虽然充分发挥 了高校和企业的优势, 但可能会陷入关于权利的混乱状态, 同样非常不利于隐形创业知识的 转移。

\section{2 .2 效率不足}

浙江高校的科研成果多，比如发表的创新论文、报告以及创业比赛获奖项目、专利等， 但是很多并没有被使用起来, 没有转化为有效的创业成果; 同时, 创客空间的相关设备耗资 巨大，但仅对相关专业以及人员开放，使用申请制度繁琐，导致了设备使用率不高，同时， 很多省内高校的创客场所因为是先后设立的, 所以较为分散, 没有将其联合起来, 导致了资 源的闲置与浪费; 浙江高校拥有大量的社会资源, 比如有合作关系的企业, 创业经验丰富的 校友, 但是, 并没有去很好的利用起来。以上三点, 严重阻碍了创业隐性知识的生成和转化, 对创业隐性知识的转移非常不利。

\section{2 .3 创客空间属性有误、知名度不足}

首先，一个好的创客空间应该根据自身高校的特点以及校内学生的相关需求来设立，有 自己的核心力，不能完全照搬硬抄其他优秀的创客空间，温州大学的创客空间就是依据自身 的特点和学生需求设立的，但是浙江高校的其他创客空间仍然存在“模仿”的痕迹; 其次, 有 些完全是为了响应上级要求, 盲目建设, 或者仅仅将自己之前的相关场所改名, 有名无实; 最后, 由于宣传力度不足, 很多在校学生都是未闻其名, 不知道自己学校有创客空间或者他 在哪里, 打击了学生的创业热情, 降低了学生的参与度。这些都对创业隐性知识的生成产生 了很大的阻碍, 不利于创业隐性知识的转移。

\section{2 .4 制度缺失}

浙江高校受到以往的管理经验以及体制制度的影响, 对创客空间的建设缺乏充分的了解, 建设途径和目的不明确, 没有将创客空间的日常纳入整个学校的人才管理和创业教育的体系 之中，具体的创客空间日常管理的相关管理制度、考核体系等设立的不完善。严重影响创客 空间运行, 没有给创业隐性知识营造一个良好的环境, 浙江师范大学网络经济创业园就存在 这样的问题。

\section{2 .5 盈利不足}

浙江高校创客空间的创客项目多为初创, 本身不具备造血能力,还需要诸多投入, 并且, 创客多为大学生, 本身并没有太多的收入, 而众创空间本身是偏向公益性质的平台, 盈利不 是主要目的, 并且又是高校设立的, 所以无法向创客收取太多的费用。另一方面, 创客空间 本身的投入巨大，持续运营成本也不小，所以，如果创客空间没有足够的资金来源，那么， 创客空间的可持续运营将大受影响, 这也很大程度上影响了创业隐性知识的生成与转移, 这 是几乎所有浙江高校创客空间的通病。

\section{4.基于创业隐性知识转移视角的国内外高校创客空间运营模式成功经验借鉴}

\section{1 国内外高校创客空间运营模式成功经验}

目前国外的比较好的高校创客空间分别是麻省理工学院媒体实验室（MIT Media Lab）、 纽约大学 ITP 项目、加州大学伯克利分校社会利益信息技术研究中心（Berkeley CITRIS）以 及斯坦福大学设计学院 (Stanford D. school)。麻省理工学院媒体实验室拥有两幢大楼, 是高 度自由化, 透明度高, 工作室化的六层建筑。里面也有小型的制造实验室, 加工设备包括工 业级 3D 打印机、木工加工中心、数控水切割机床等, 必须接受相关设施的操作培训并且不 能单独操作。

当前国内我国已建成的高校众创空间比较有代表性的有天津大学创新创业教育中心、清 华大学的 i.Center, 香港科技大学的创业中心以及深圳大学“创客 BOX”等。例如清华大学的 i.Center, 加工设备都是工业级的, 这是一般的创客空间所无法比拟的。教师教学通过与项目 
的结合来实现，这让学生在实践中成长，提高了能力。i.Center 将新一代的信息技术导入基础 设施, 打造了三大平台, 创客课程在线平台、创客团队项目管理平台、创客活动管理平台, 便利化了学生们的活动与选择。

\section{2 国内外高校创客空间运营模式成功经验借鉴}

\subsection{1 准确定位}

部分高校对创客空间的定位有一定的偏差，仅仅只是将创客空间认为是传统的创业孵化 器、科技创业园等, 没有准确的解读创客空间的意思, 所以浙江高校应该进一步明确创客空 间的概念, 特点等相关内容, 清楚自身定位, 扫除认知错误的地方, 然后根据自身的特色与 校内学生的需求、结合优势专业与资源以及当地的企业状况, 注重自身创客空间的差异化, 以及特色化发展。有助于构建良好的创业知识生成与转化环境, 有利于创业隐性知识的转移。

\subsection{2 开源节流}

其一，加大与当地知名企业的合作，推动优秀创业项目与企业资金的有机结合，也可以 寻求社会资本帮助，例如社会天使投资人、投资机构以及校友资助等，加快创业成果的出现， 可以向成功的创业项目收取一定的费用; 其二，提供增值服务，向创客团队提供创客空间之 外的各类服务, 比如帮助办理各类手续, 创客心理辅导等, 或者向社会人士开放创客课程收 费; 其三, 创客空间与企业、政府以及社会组织合作, 为创客团队提供一体化的低成本服务, 比如行业机构可以提供有效的咨询、监督服务, 中介机构可以使项目尽快与市场对接, 从而 降低创客空间运营成本。

\subsection{3 提高知名度}

创客空间在 2015 年开始被公众所知, 在 2016 年热度略有下降。提高创客空间的知名度, 不仅有利于大众对其的准确认知, 让更多的人关注创客空间, 进入创客空间, 而且可以吸引 更多的社会资源，有利于创客空间的建设与完善，非常有利于创业隐性知识的转移。

\subsection{4 完善创业教育}

从浙江高校的实际出发, 将创客空间的建设与学校的创新创业教育结合起来, 纳入学校 人才教育与培养体系。坚持以学生创客为目的, 综合各个学科的相关知识, 不同学科背景的 导师互相协作, 开发高效的创业课程; 邀请企业的相关人员以及社会知名创客对高校科研成 果做检测与评估，对可以转化的创新成果进行立项考察，提高科研成果的转化率。

\section{5.基于创业隐性知识转移视角的浙江高校创客空间运营模式创新}

创客空间为学生创业提供了场所、工具和创业导师, 通过学生的创业实践活动增强了学 生的创业能力, 形成了优秀的创业精神, 也为创业隐性知识的转移提供了有利条件, 有极其 强大的促进作用, 关于基于创业隐性知识转移视角的浙江高校创客空间模式, 本文提出了以 下几点对策。

\section{1 创客空间环境创新}

\section{1 .1 建立开放式物理空间}

开放式物理空间内部高度透明，能够看到其他团队的创业进程以及创业工作，这有利于 推进隐性知识的转移与生成, 整个创客空间内部学生成员相互交流, 增加成员之间的联系与 协作，还能够博采众长，汲取精华，为自己的创业提供建议与经验。

\section{1 .2 及时跟进先进的加工设备}

麻省理工学院媒体实验室（MIT Media Lab）拥有的小型的制造实验室加工设备包括工业 级 3D 打印机、木工加工中心、数控铣床、数控水切割机床等, 这让实验室成员能更好的进 行实践操作, 增强创业能力和创业精神的培养。所以, 更优秀的设备可以让创客空间内部学 
生成员更好的进行创业实践, 有利于创业隐性知识的获取和生成, 并丰富创业隐性知识, 也 有利于隐性知识的转化。

\section{1 .3 构建创业文化氛围}

通过创业会议、创业论坛以及与之相关的创业演讲、辩论等活动来对创客空间进行宣传, 增强学校内部的创业氛围, 让更多的学生了解创业, 了解创客空间, 对其产生兴趣, 吸引越 来越多有创业想法的学生来主动投入创客空间, 学生的主动性越强, 其隐性知识的转移也越 加潜移默化, 越有效。

\section{2 推进利于隐性创业知识转移的创客空间制度创新}

\section{2 .1 创客空间进出制度}

对入驻的创业团队进行相关条件审核, 确认创业团队成员是否具有一定的创业能力和强 烈的创业意愿, 并且确保创业团队的创业想法具有现实可行性等。

\section{2 .2 创客空间团队管理制度}

对入驻团队的管理方式、考核期限以及团队扶持的相关情况进行说明，并按照管理制度 严格执行，若违反，创客空间有权进行相应的处罚。

5.2 .3 制定严格规范的设备器材使用和保养制度

严格规范的使用制度可以有效防止设备器材的不正当使用而造成的损坏，也可以避免因 操作不当所造成的人员受伤; 聘请器材设备保养师和制定保养制度可以有效延长设备的使用 时间。这些制度都使创客空间的运行更加高效, 在一定程度上保证了创业隐性知识的生成和 转移。

\section{3 加大利于隐性创业知识转移的创客空间资源投入}

\section{3 .1 师资力量创新}

其一高校内部的有创业相关经验的教师可以担任创客空间的团队导师，指导创客空间学 生团队的创业实践, 这不仅有利于教师的创业隐性知识向创客空间学生转移, 也有利于培养 学生的创业观念、创业精神, 亦使创业成果更有质量。其二邀请知名企业家和成功创业的校 友举办讲座、座谈会等, 为创客空间学生们传授经验以及教训。高校如果有条件的话, 亦可 以邀请部分企业人员和成功校友和高校老师组成教学团队, 制定创业课程, 可以更有效地促 进创业隐性知识的转移。

\section{3 .2 运营资金来源创新}

目前创客空间的运营经费来源一般为高校、企业和政府专项资金，但是高校支持资金一 般不足，企业资金大多数用在企业本身认为有潜力的项目上面，政府的专项资金申请较为困 难, 所以开拓出新的资金来源是很有必要的。首先, 对于非高校师生的创客以及已经成功正 常盈利的创业项目, 可以收取相应的租金来维持创客空间的运营。其次，社会捐助也是一个 经费来源途径。

\section{4 建立利于隐性创业知识转移的创客空间平台}

\section{4 .1 线上平台建设}

网络平台的信息交流可以有效促进隐性知识的内化和转移。其一、运用先进的信息技术 为创客空间打造一个线上平台用于创客空间的管理、运行以及创客空间学生们的信息交流。 创客空间可以设立自身的贴吧、论坛、微波和公众号等多种对外对内交流网络工具, 不仅有 利于创客空间的对外宣传, 也有利于创客们的创业交流, 促进创客们对创业知识的深入理解。 其二、搭建政府、企业、公益机构和高校等多主体参与的创业实践平台, 为创业团队提供全 方位、多领域以及多元化的服务。 


\section{4 .2 线下平台建设}

其一、定期举行创客交流活动，创客们之间互相探讨，增进了解，促进隐性知识的转移 与内化。其二、定期举办政府、企业、公益机构和高校等多主体参与的展示活动, 一方面有 利于创业资金来源的多元化，另一方面也可以对自己的创业项目有更深入的了解，及时把握 方向, 利于创业项目走的更远。线下平台的建立十分有利于创业隐性知识的生成和转移、内 化。

\section{5 发挥政府服务职能，推进创客空间建设}

发挥政府的服务职能, 不仅有利于创业项目的顺利进行, 而且能帮助创客空间成员减少 时间成本，为创业隐性知识的生成与转移提供了强大的支持。

\subsection{1 便利服务}

简化关于创客空间的相关登记手续流程, 提供“一站式”服务, 帮助创客空间的创业项目 完善手续及相关文件，使创客空间成员有更多时间和精力去进行创业项目的实践。

\subsection{2 政策支撑}

确保各项政府优惠政策积极落实到创客空间成员身上，在补贴、税收方面给予一定的优 惠，帮助创业项目的发展。

\section{References}

[1] Fan Wang, Li Hao, Changjin Jiang. The Impact of Public Space Development on University Innovation and Entrepreneurship Ecology[J]. Research and discussion, 2016(4): 125-127.

[2] Jianxin Yang, Hongbin Sun, Shuangshou Li et al. American College Innovation Education Laboratory and Social Maker Space Investigation[J]. Modern education technology, 2015, 25(5): 27-32.

[3] Suwei Zhang. Research on the Implementation Plan of Entrepreneurship Education of Local Colleges Students in Hebei Province from the Perspective of Tacit Knowledge[J]. Cultural Education, 2011(48): 187-196.

[4] Sufang Wu. On the role of tacit knowledge in college students' entrepreneurship education[J]. Vocational Education Newsletter, 2014(23): 44-45.

[5] Wenliang Jiang. Construction of college students entrepreneurship education system based on tacit knowledge[J]. Journal of Yangzhou University(Higher Education Research Edition), 2011, 15(6): 60-63.

[6] Zhong Liang, Li Pan. Research on the Model of University Entrepreneurship Education Based on the Perspective of Tacit Knowledge[J]. Journal of Huaiyin Institute of Technology, 2012(4): 76-79.

[7] Youwei Wang, Zhanan Chen. From Innovation to Entrepreneurship: The Construction Mode of University Maker Space in the United States and Enlightenment[J]. China Electrification Education, 2016, 8(355): 1-6.

[8] Ying Wang, Diangui Huang. The response and improvement of undergraduates' creative practice teaching under the background of the maker space: Taking the science and engineering university students as an example[J]. High School Journal, 2015(21): 72-73. 